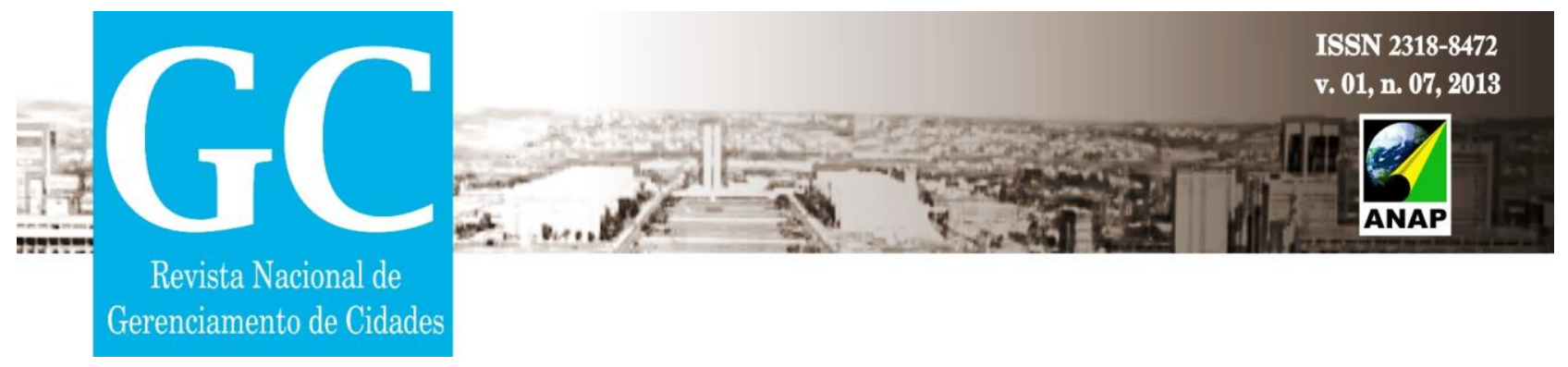

\title{
ANÁLISE DA FORMAÇÃO DO BAIRRO SÃO JORGE NA CIDADE DE UBERLÂNDIA (MG)
}

\section{Cristiane Aparecida Silva Moura de Melo ${ }^{1}$}

\section{Paulo Henrique Kingma Orlando²}

Resumo: Este artigo trata do processo de formação do bairro São Jorge na periferia da cidade de Uberlândia (MG), inicialmente de forma irregular obteve sua regularização através do projeto lei 6.622 de 10 de maio de 1996. Devido a sua informalidade, não possui um planejamento adequado, inicialmente foi ocupado de maneira inapropriada e isso reflete nas vias públicas. Na gestão do prefeito Ferolla foi implementada a integração deste com outros sete bairros, além da formação de um centro comercial, o qual possui uma grande gama de comércios, além de serviços bancários. Em relação a segurança, que é um problema enfrentado pelos bairros periféricos, foi implantado pela Policia Militar de Minas Gerais o grupo GEPAR (Grupo Especializado de Policiamento em Áreas de Risco). Para a constituição do artigo foram realizados levantamentos bibliográficos e trabalhos de campo. Assim foi possível averiguar que com o crescimento da cidade, ocorreu uma maior valorização dos terrenos na área central da cidade e como consequência disso os trabalhadores que possuíam uma menor renda, passaram a procurar áreas cujo valor agregado do terreno fosse mais baixo, e como consequência disso são constituídos os bairros periféricos como o São Jorge e que com o decorrer do tempo estes passam a serem reconhecidos pelo governo municipal, passando a geri-los e como resultado há a implementação de serviços e a instalação dos sub centros que

\footnotetext{
${ }_{1}^{1}$ Mestranda em geografia da Universidade Federal de Goiás - Campus Catalão crisapa3179@gmail.com.br

2 Professor Doutor em geografia da Universidade Federal de Goiás - Campus Catalão phorlando@yahoo.com.br
} 


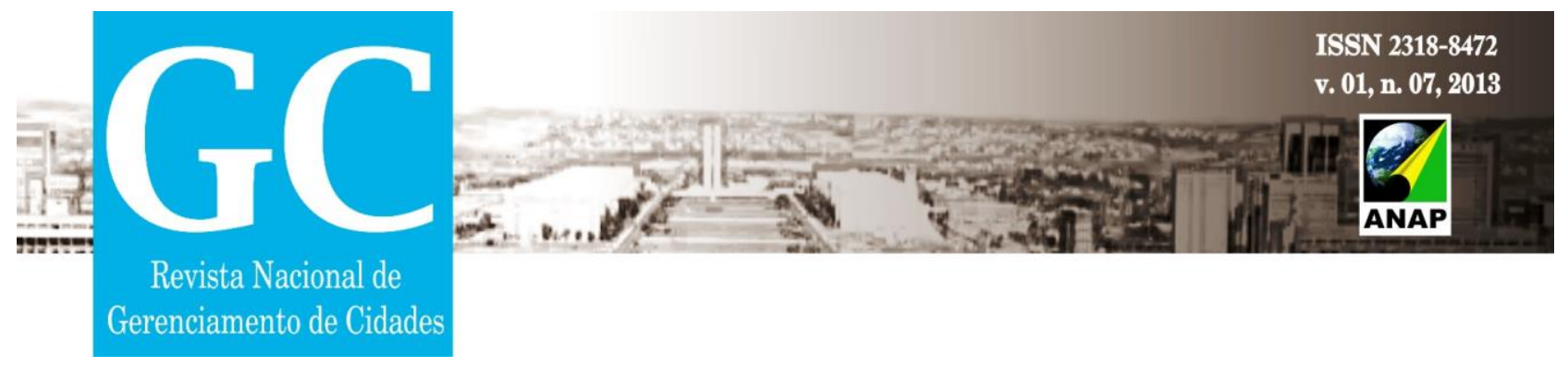

atendem a população local, além de se tornarem de grande importância para a cidade, apesar de que o planejamento é deficitário.

Palavras-Chave: Planejamento. Periferia. Integração.

\section{INTRODUÇÃO}

A cidade de Uberlândia (MG) o processo de urbanização iniciou-se no ano de 1890 com a construção da estrada de ferro Mogiana que trouxe o progresso para o lugar que até então era um local de passagem de tropeiros que levaram mercadorias do estado de São Paulo para Goiás.

Com o avanço trazido pela estrada de ferro foram surgindo indústrias e comércios de vários ramos na cidade de Uberlândia. Isso causou um espalhamento da cidade e modificações na paisagem. Segundo Santos (2008) "Cada lugar é teatro de combinações pouco duráveis, cujo fator de mudança é esse dado global. Cada lugar é, assim, a cada instante, objeto de um processo de desvalorização e revalorização, onde as exigências de natureza global têm um papel fundamental". A partir dessa colocação podemos observar que em decorrência do crescimento da cidade os terrenos mais próximos ao centro urbano passam a ter um valor agregado maior e com isso as pessoas com menor poder econômico passam a procurar a periferia na tentativa de reproduzir o seu modo de vida.

Assim as pessoas que possuíam uma melhor condição socioeconômica moravam mais próximos ao centro urbano, enquanto as que não tinham moravam nas áreas próximas a esse centro, o que na maior parte demonstrava a exclusão dessa massa. Como coloca Maricato (2000) dizendo que a exclusão urbanística acaba sendo representada pela grande ocupação ilegal do solo o que acaba não correspondendo ao planejamento urbano. 


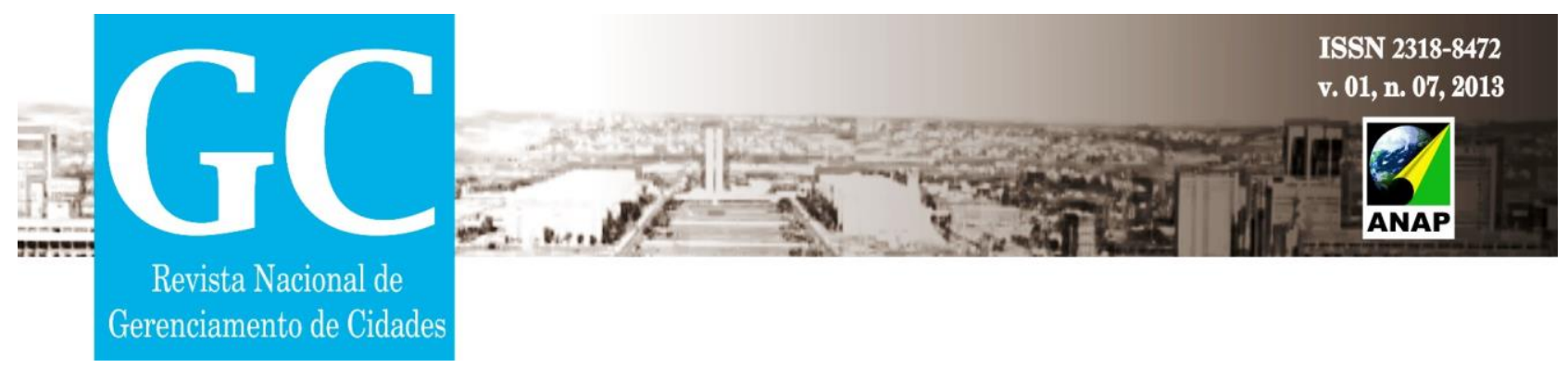

A formação da área periférica da cidade devido ao espalhamento da mesma e de acordo com as necessidades de seus trabalhadores que recebiam baixos salários e não tendo como pagar por uma moradia na área central, acabam buscando áreas mais periféricas e muitas delas são iniciadas a partir de invasões de parcelas do solo.

E assim tendo vista a fuga dos centros urbanos em busca de um menor custo de vida nas periferias e da identidade de seus moradores, bairros sem um planejamento adequado são criados. Isso leva ao prejuízo do desenvolvimento integrado de uma cidade, pois os bairros periféricos não se desenvolvem de forma continua e planejada.

Quando isso ocorre surgem uma serie de problemas como falta de transporte público, falta de coleta de resíduos sólidos, sistema viário deficitário, ausência de espaços e equipamentos públicos, falta de unidades de saúde, escolar, lazer e segurança, ligações clandestinas de água, luz e esgoto, ruas sem pavimentação e falta de saneamento básico. Outro problema surge da incapacidade do Estatuto da Cidade não poder implantar melhorias na infraestrutura desses bairros até que haja a sua regularização.

$\mathrm{Na}$ cidade de Uberlândia esse processo de formação de periferia ocorreu em várias áreas como o Morumbi, Joana D’arc, Dom Almir e São Jorge, todos esses bairros foram ocupados de forma irregular. Recentemente essas áreas de invasão foram formalizados como bairros e por isso receberam os mobiliário urbano e saneamento.

Em decorrência disso o trabalho se propõe realizar um estudo no que tange a infraestrutura publica do São Jorge que a principio não possuiu um planejamento urbano adequado, até mesmo o parcelamento do solo inicialmente não atendeu a Lei Orgânica do Município, e quando se observa o local verifica-se uma região típica de periferia com ruas estreitas e tortuosas, calçadas de várias larguras e com pisos irregulares o que prejudica a mobilidade das ruas e como isso influencia no cotidiano dos moradores que somam mais de 27.000 crescendo tanto em número de domicílios (horizontalmente). E a partir disso o foco do trabalho a averiguação de como do processo de formação do bairro São Jorge na cidade de Uberlândia (MG). 


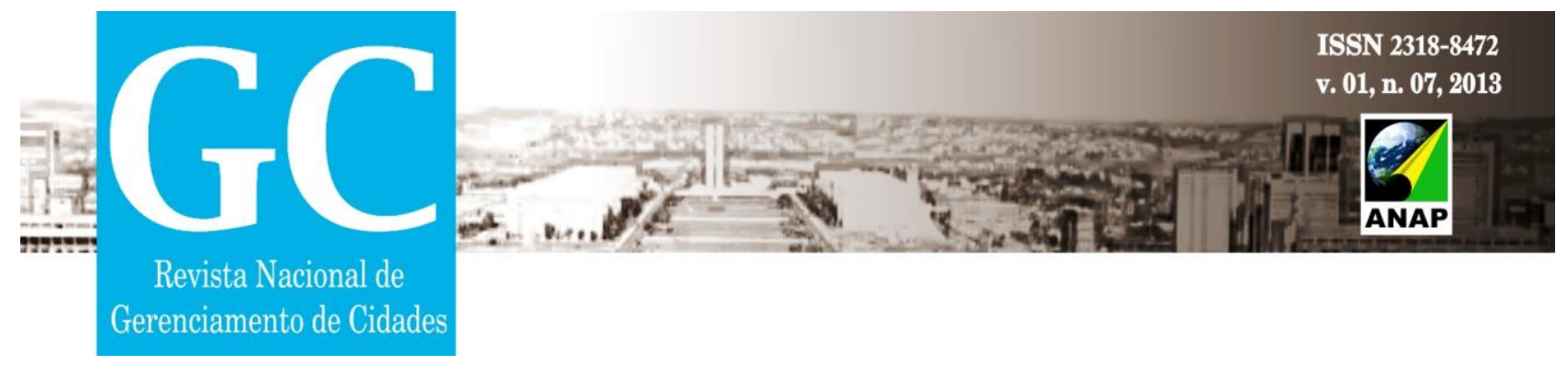

DESENVOLVIMENTO

A área de estudo está inserida na cidade de Uberlândia, a qual último recenseamento realizado pelo IBGE (Instituto Brasileiro de Geografia e Estatística) no ano de 2010, a cidade conta com 604.013 habitantes, uma extensão territorial de 4.115,206 $\mathrm{km}^{2}$ e uma densidade demográfica de $146,78 \mathrm{hab} / \mathrm{km}^{2}$ o que a torna a segunda maior cidade do estado de Minas Gerais. O município, no qual a cidade pertence, localiza-se entre as coordenadas geográficas de latitude $18^{\circ} 30^{\prime}$ e $19^{\circ} 30^{\prime}$ Sul e, $47^{\circ} 50^{\prime}$ a $48^{\circ} 50^{\prime}$ de longitude Oeste do meridiano de Greenwich, na microrregião do Triângulo Mineiro, no oeste do estado de Minas Gerais (LIMA, 1989). Além do distrito sede, o município conta ainda com mais quatro distritos: Cruzeiro dos Peixotos, Martinésia, Miraporanga e Tapuirama.

Uberlândia interliga-se a outros centros pelas rodovias BR-365, BR-452, BR-050 e BR-497. Limita-se ao Norte com os municípios de Araguari e Tupaciguara; ao Sul com Uberaba, Veríssimo e Prata; a oeste com Monte Alegre de Minas e a leste com Indianópolis.

Quanto à história da cidade, Uberlândia foi fundada a partir do desbravamento do Sertão da Farinha Podre, no século XIX, em terras do município de Uberaba, sendo elevada à categoria de município em 31 de agosto de 1888. A partir da metade do século passado, além das atividades agrícolas, a cidade voltou-se para interesses comerciais e também industriais, consolidando-se como um centro polarizador da economia da região, capaz de atrair pessoas e investimentos externos.

Sua economia baseia-se nas atividades agropastoris e comerciais, com destaque para a soja, arroz, milho, gado bovino, avicultura, além do comércio atacadista, que distribui produtos industrializados para várias regiões do país. Além de desenvolver um vasto setor de serviços.

A vegetação nativa do cerrado que havia no local onde esta localizada a cidade foi retirada para dar espaço às edificações, juntamente com isso houve a 


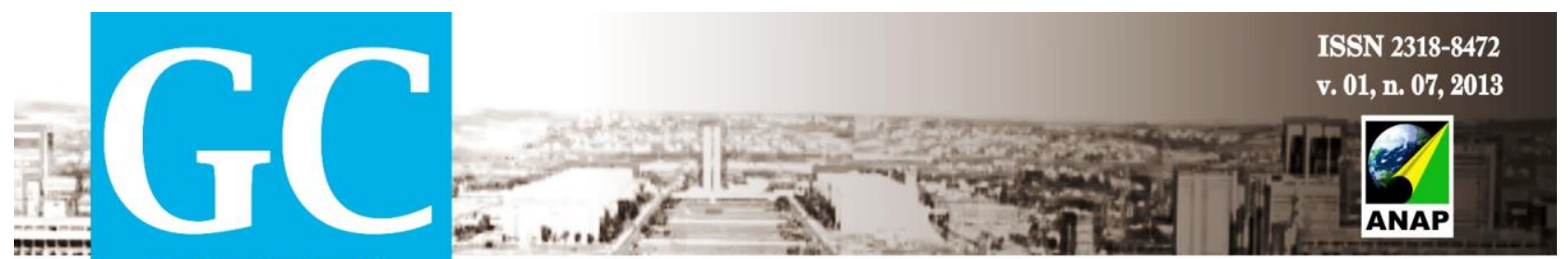

Revista Nacional de

Gerenciamento de Cidades

impermeabilização do solo o que acabou acarretando uma nova dinâmica ambiental inclusive com maior sensação térmica, além da canalização dos cursos d'água que foram colocados sob as avenidas.

No processo de urbanização da cidade de Uberlândia (MG) a vegetação nativa, cujo domínio fitofisionômico é o do cerrado, foi retirado para dar espaço à malha urbana $\mathrm{e}$ a produção agrícola. A figura 1, a seguir, mostra a localização da cidade.
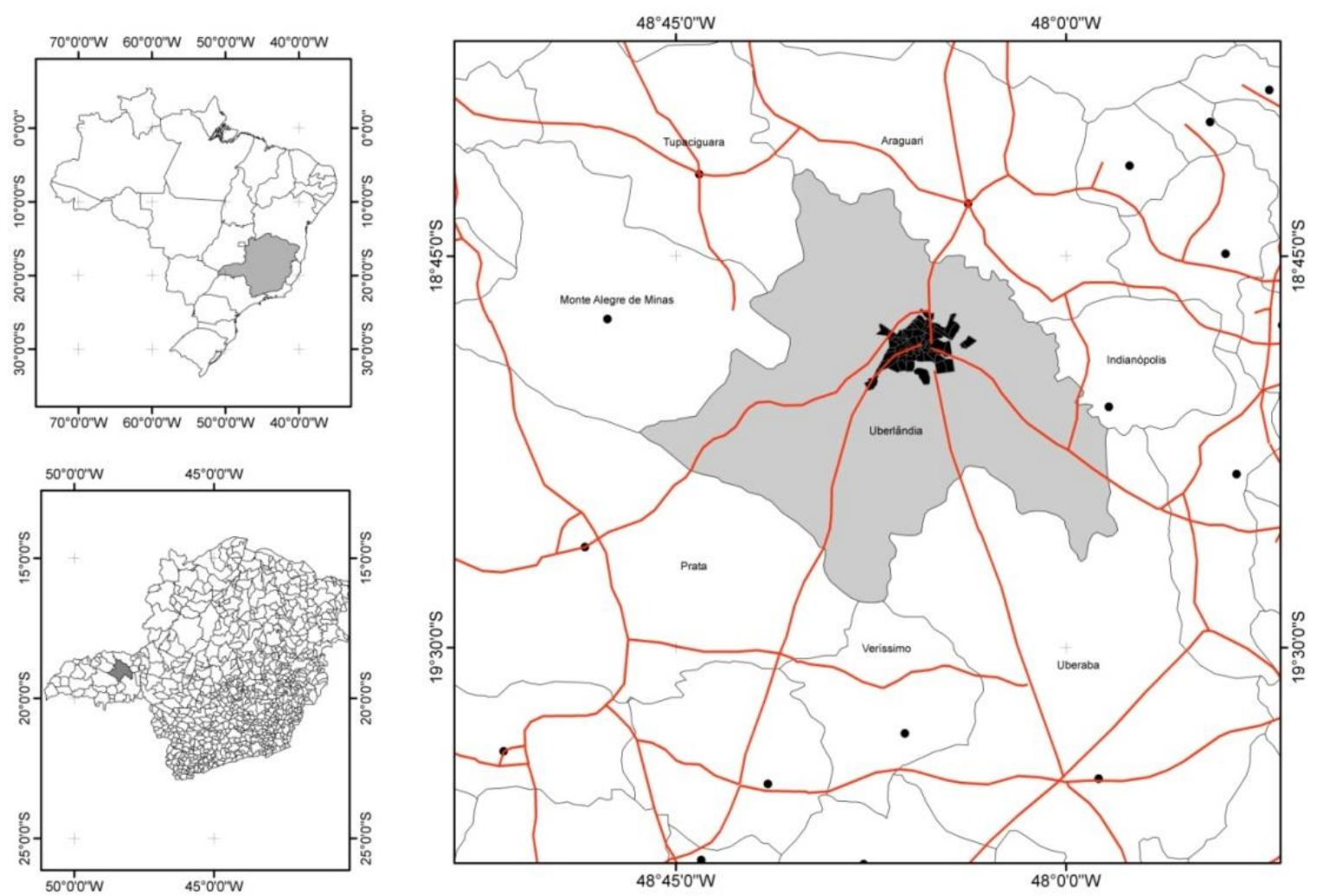

Legenda
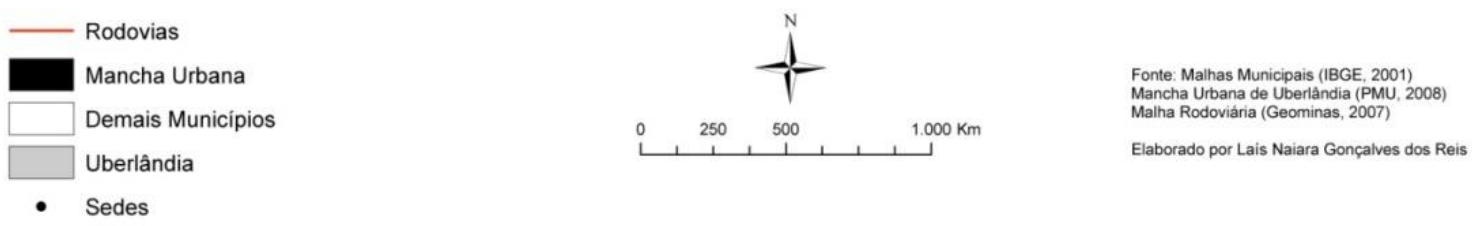

Figura 1: Localização da cidade de Uberlândia (MG)

Fonte: REIS, dos. L. N. G. 


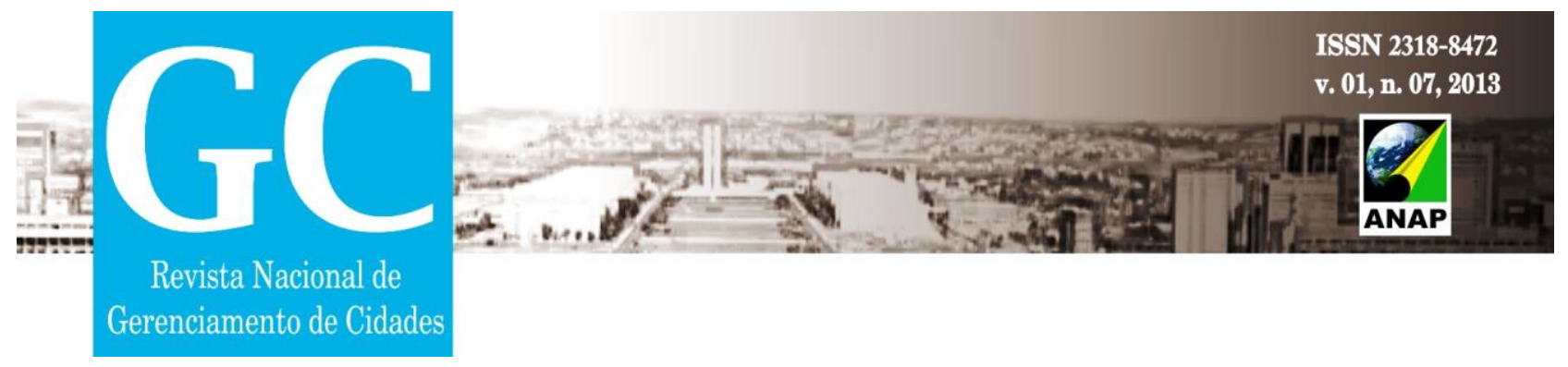

O bairro São Jorge delimitado pelas avenidas Seme Simão, Serra Bodoquena e BR 050. que foi criado pelo projeto lei 6.622 de 10 de maio de 1996, está localizado no setor sul da cidade de Uberlândia (MG), no ano de 1995 o prefeito Paulo Ferolla decidiu unificar os bairros da cidade para facilitar a administração. A figura 2 demonstra a localização do bairro na malha urbana da cidade.

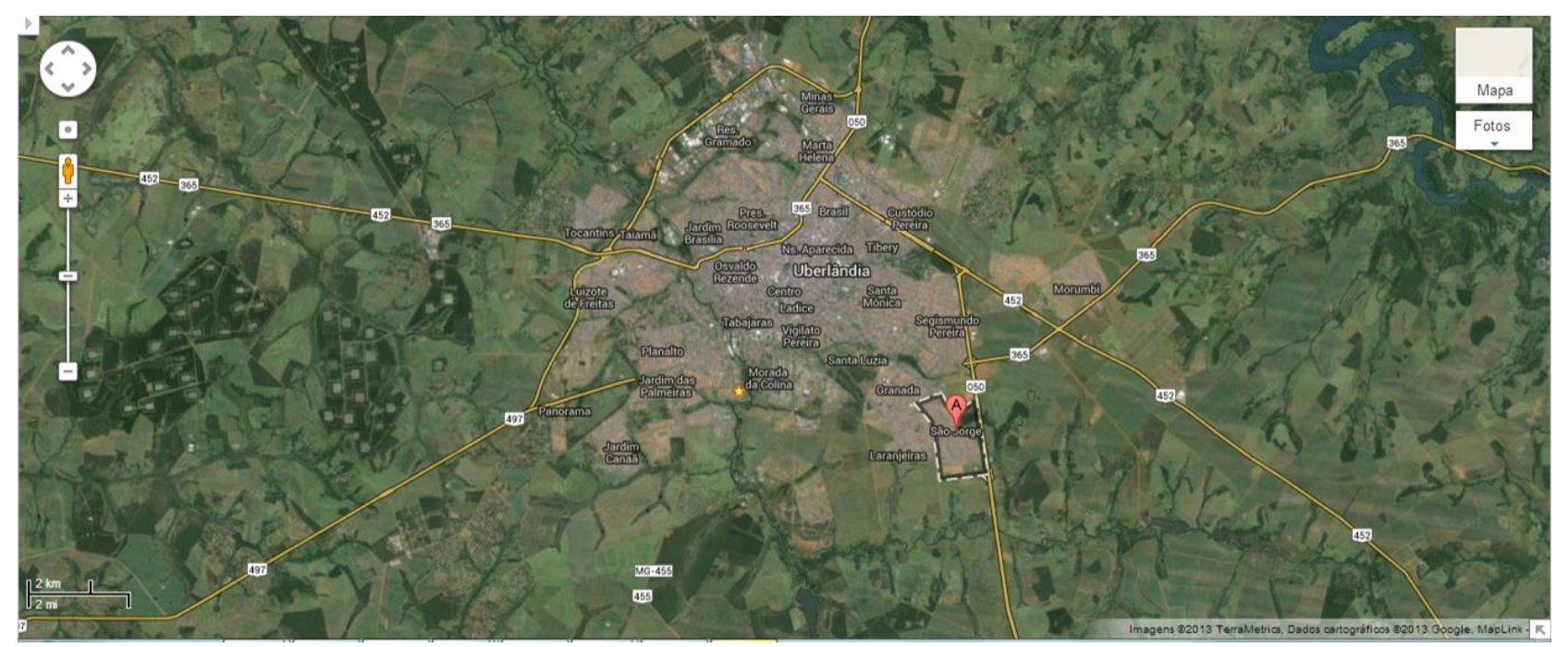

Figura 2: Localização do bairro São Jorge na malha urbana da cidade de Uberlânida (MG) Fonte: Google maps

O bairro foi criado de forma irregular, ou seja, sem um planejamento urbano adequado, no inicio não possuía serviços básicos como a coleta de resíduos sólidos urbanos, esgoto, pavimentação das ruas, telefones públicos e residenciais, contando apenas com o sistema de fornecimento de energia elétrica e de distribuição de água.

Mesmo sem a prestação desses serviços básicos o bairro foi se desenvolvendo e novas edificações continuaram sendo construídas, pois os valores dos lotes eram acessível à população de menor renda. Mas na década de 1990 ele foi regularizado pela prefeitura, através do projeto lei 6.622 de 10 de maio de 1996. A partir disso foram implementados serviços de água, esgoto, luz, pavimentação das ruas, implantação do transporte público dentre outros tipos de serviços. 


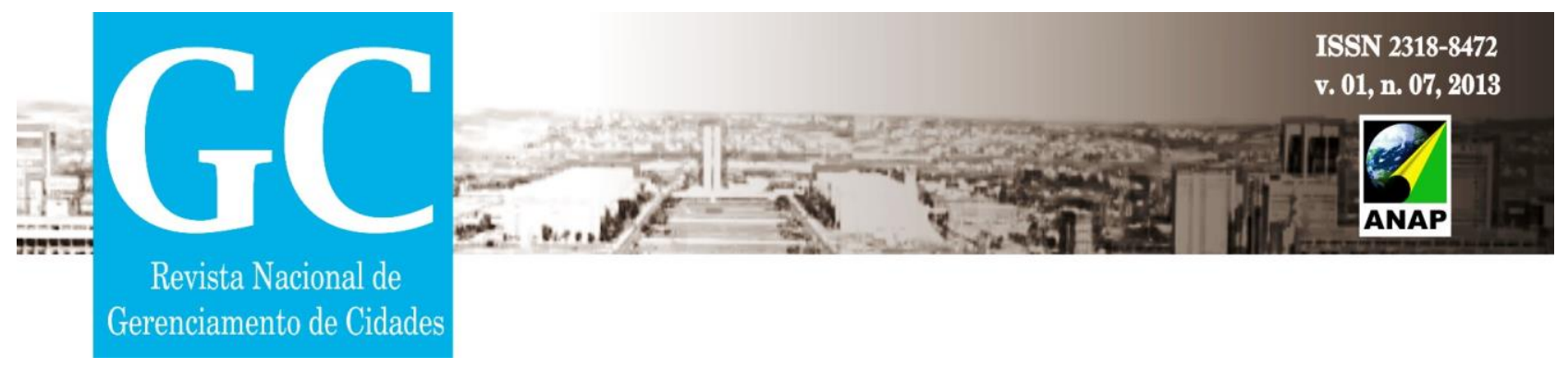

Esse bairro é, atualmente, considerado o segundo maior da cidade de Uberlândia (MG) devido a sua integração aos bairros São Jorge I, II, III, IV e V, Quinhão, Jardim das Hortências, Parque Primavera, Campo Alegre, São Gabriel, Viviane e Seringueiras. Conta com um centro comercial com vários tipos de comércio, casas lotéricas, três agências bancárias, postos de gasolina, prestadores de serviços em vários ramos como consertos de aparelhos celulares, computadores, dentre outros, bares, padarias, possui um grande hipermercado pertencente a uma rede, serviços públicos de saúde, igrejas evangélicas e católicas, praças publicas. No que tange a educação possui várias escolas particulares de ensino infantil, EMEI (escola municipal educação infantil), escola estadual de educação básica (ensinos fundamental e médio). A figura 3 retrata uma das ruas do centro comercial do bairro.

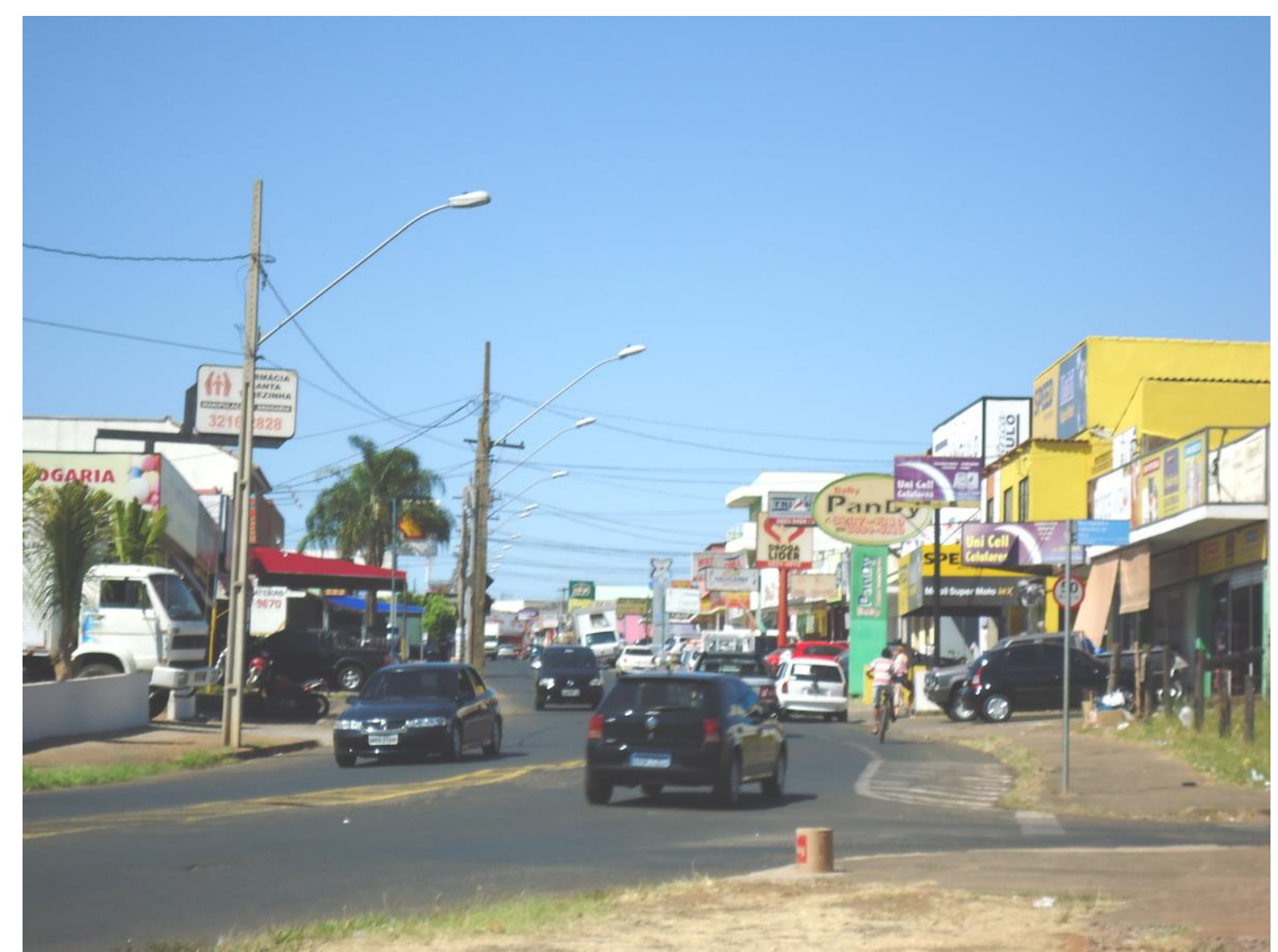

Figura 3: Rua do centro comercial do bairro São Jorge Fonte: MELO, C. A. S. M. 


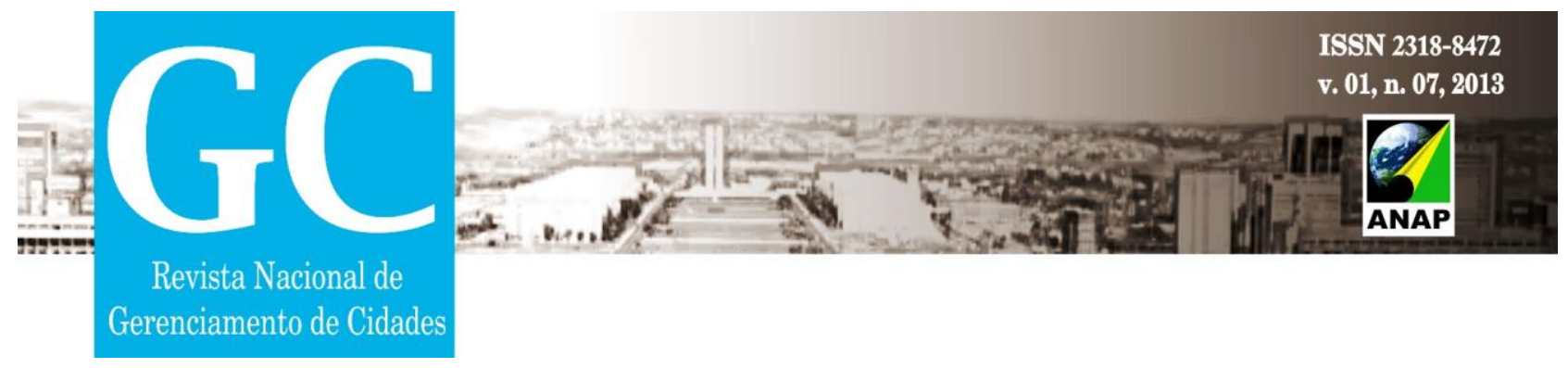

Em relação aos tipos de modais de transporte observa-se que as pessoas se deslocam através de bicicletas, carros, motos além do transporte público, mas dentre esses modais o que predomina na periferia do bairro é a utilização de bicicletas, enquanto na região central o uso de veículos automotivos na maioria das vezes com mais de dez anos de uso que circulam em ruas estreitas e tortuosas sendo a maioria de vias duplas. A figura 4 retrata o modelo de uma rua bem característica do bairro a qual inicia-se com uma rua comercial denominada Taxista Fabio Cardoso caracterizada por ser estreita de mão dupla que permite estacionamento, ao meio se transforma em uma larga avenida denominada Serra da Mantiqueira.

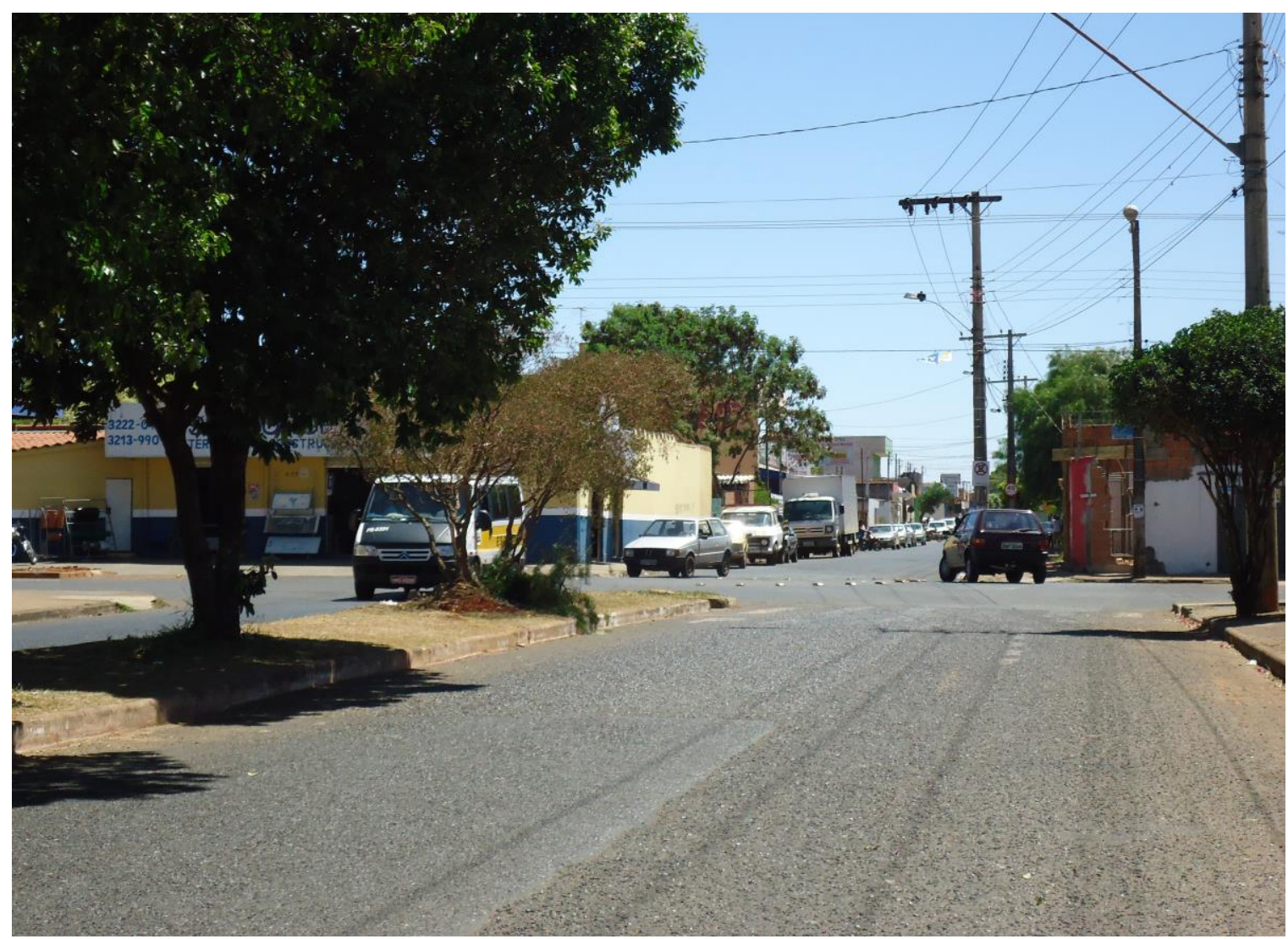

Figura 4: Rua Táxista Fábio Cardoso que dá continuidade à avenida Serra da Mantiqueira Fonte: MELO, C. A. S. M.

As calçadas não possuem o padrão adequado, que segundo a ABNT NBR 9050 é de 1,5 metros sendo admissíveis de até 1,2 metros e com piso regular facilitando 0 


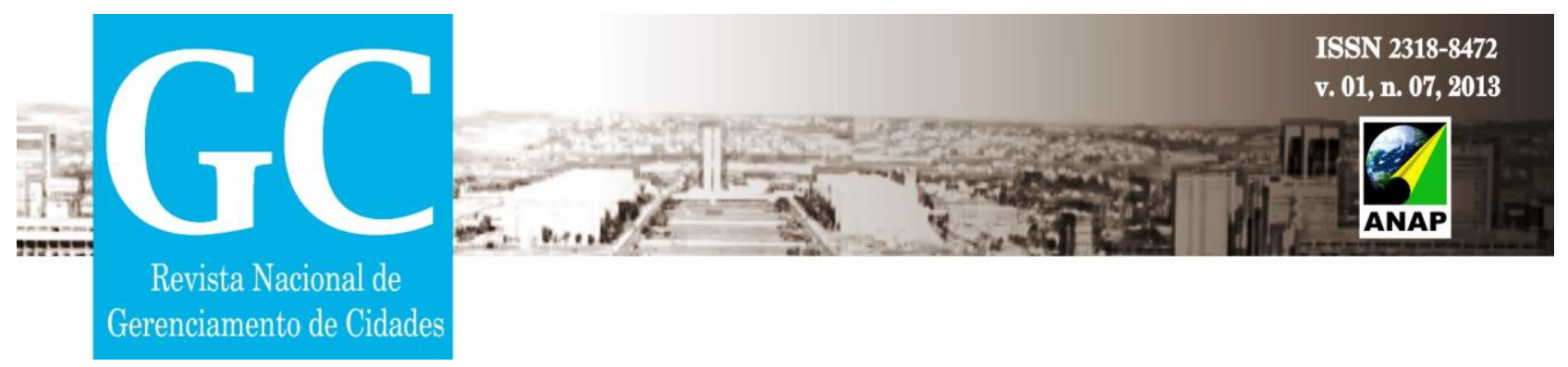

deslocamento das pessoas com maior fluidez, as mesmas são estreitas, possuem altura, tamanho e piso com diferentes padrões o que muitas vezes leva ao transtorno na circulação de pessoas, além de que nas áreas comerciais são utilizadas para a exposição de mercadorias.

Em relação à segurança foi implantado pela Policia Militar de Minas Gerais o grupo GEPAR (Grupo Especializado de Policiamento em Áreas de Risco), que promove a segurança da população através da prevenção e repressão aos crimes violentos contra a comunidade de uma forma geral, esse grupo foi implantado devido ao grande número de crimes na região.

A partir de levantamentos bibliográficos e convívio com o bairro, percebeu-se que apesar do bairro ter quase décadas e no primeiro semestre do ano de 2012 ter se tornado um subcentro, o que é de grande relevância para a cidade, já que o bairro segundo dados da Prefeitura Municipal de Uberlândia o número de morados é superior a 27.000 e possui uma área de $4.817 \mathrm{~km}^{2}$, possuindo assim uma grande relevância para a cidade, além da integração com os demais bairros que foram citados à priori.

Para afirmar a importância do bairro São Jorge Filho e Alves (2006) relatam que o forte desenvolvimento das cidades médias possibilitou a ocorrência, de transformações em âmbito interurbano, como a valorização das cidades médias perante a hierarquia urbana; e de modificações na estrutura intra urbana dessas cidades, pela instalação de novas centralidades, as quais são representadas pelos subcentros, eixos comerciais, áreas especializadas e shopping centers. Assim ocorre a verificação de que com 0 decorrer do tempo com o crescimento da cidades ocorre a descentralização dos centros urbanos.

E ainda para afirmar a importância da do bairro como sub centro Correa (1995) coloca que a descentralização origina diferentes formas espaciais, algumas delas ocorrem de forma espontânea como os sub centros que são os bairros que possuem centros comerciais hierarquizados tendo comércios de móveis, autopeças, farmácias, clinicas 


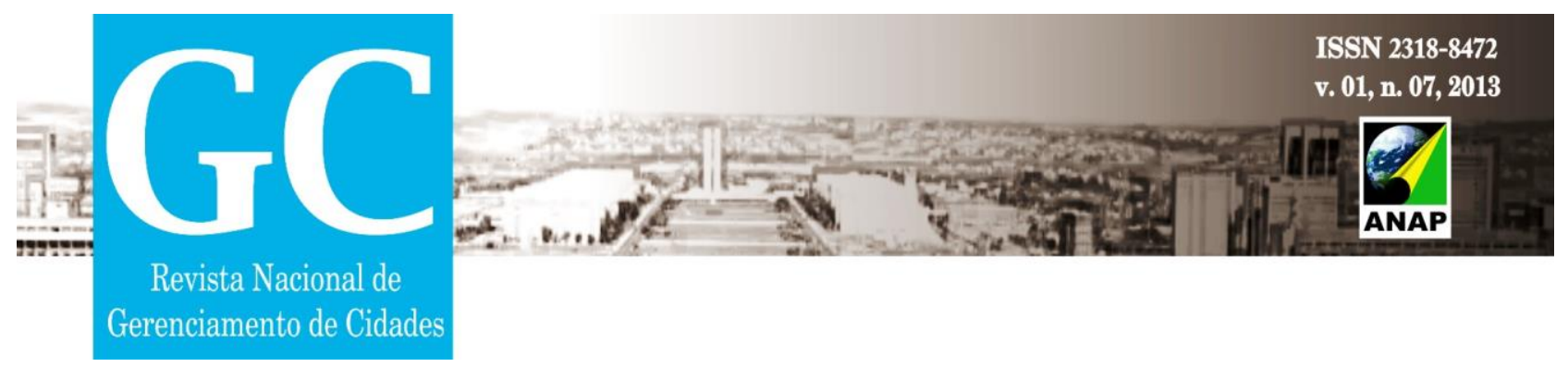

medicas e odontológicas, bancos, casas lotéricas dentre outros tipos de comércios. Algumas dessas áreas são planejadas, enquanto outras se desenvolvem sem nenhum tipo de planejamento como exemplo disso podemos citar na cidade de Uberlândia-MG os bairros Rossevelt (setor norte) que foi planejado antes de sua criação concreta e a área de estudo bairro São Jorge (setor sul) que é caracterizado por não possuir planejado.

O espalhamento da cidade conforme expõe Maricato (2000) acarreta na segregação espacial a qual demonstra as desigualdades sociais. A qual as pessoas com menor poder sócio econômico acabam buscando a periferia para poder representar o seu modo de vida, ou seja, sobreviverem com poucos recursos, mas como essas regiões são irregulares acarretam em uma série de dificuldades relacionadas à infraestrutura e a prestação de serviços urbanos considerados básicos como o transporte público, saneamento básico, rede de esgoto, ineficácia no abastecimento de água e acesso a escolas e saúde, além da maior exposição a violência, além de que os moradores sofrem com a discriminação social, já que habitam uma região mais periférica e muitas vezes violenta.

\section{CONSIDERAÇÕES FINAIS}

A partir da constituição desse trabalho foi possível averiguar que a cidade de Uberlândia (MG), na sua constituição possuía um planejamento adequado, já que as ruas de um foram geral possui o formato de tabuleiro de xadrez o que leva a uma melhor circulação de veículos.

Mas com o crescimento da cidade, ocorreu uma maior valorização dos terrenos na área central da cidade e como consequência disso os trabalhadores que possuíam uma menor renda, passaram a procurar áreas cujo valor agregado do terreno fosse mais baixo, e os com menor condições financeiras passaram a invadir terrenos em áreas mais periféricas. 


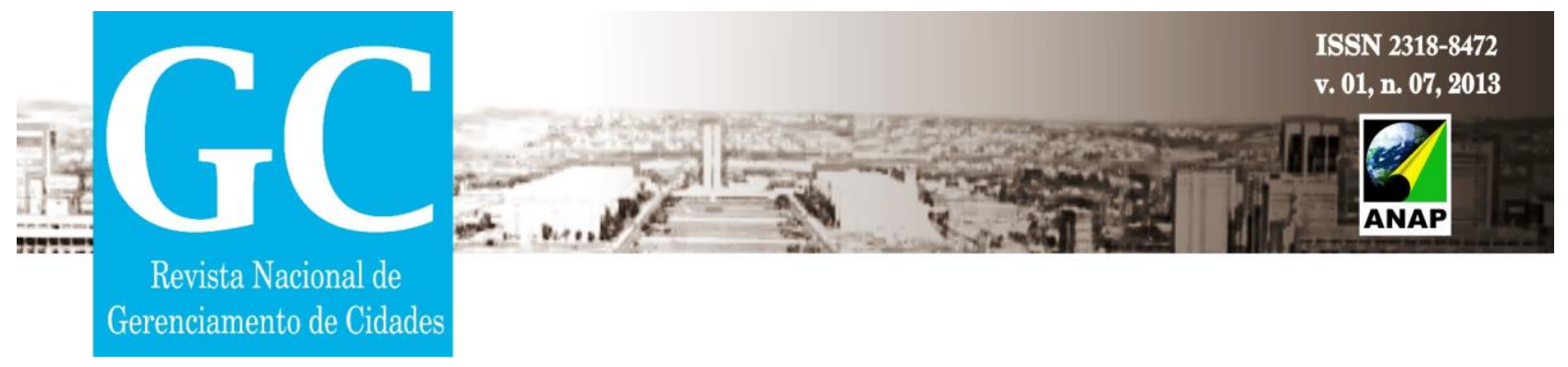

Assim se formou o bairro São Jorge, que inicialmente não possuía os serviços públicos urbanos e o mobiliário, já que esses não são prestados em áreas de invasão, por esse motivo a constituição do bairro não possui um planejamento adequado e a partir disso as ruas foram construídas de forma tortuosa, além de serem estreitas.

Com o decorrer do tempo a população desta parcela da periferia foi aumentando e com isso, ocorre um maior fluxo de veículos e pessoas o que torna-se um transtorno devido a falta de sinalização.

Mas apesar dos problemas foi implementado um subcentro, com todos os tipos de serviços e comércios ofertados na área central o que facilita para o morador que não necessita se deslocar a uma grande distancia para solucionar problemas corriqueiros.

Dessa forma é necessário que haja uma reestruturação do planejamento no bairro, no que tange os mobiliários urbano e também, nas vias colocando nas mais estreitas que possuem mão dupla em vias de mão única, pois a cada recorte temporal o bairro se expande e como resultado há o aumento da população.

\section{REFERÊNCIAS}

Associação brasileira de normas técnicas. Normas técnicas na construção civil. Disponível em < http://www.abnt.org.br/m5.asp?cod_noticia=210\&cod_pagina=962>. Acessoão em: 01 de Junho de 2012.

BICALHO, M. P.; VASCONCELLOS, E. A. Panorama da mobilidade urbana no Brasil: tendências e desafios. São Paulo: ANTP, 2006.

CARLOS, A. F. A. O espaço urbano: novos escritos sobre a cidade. São Paulo, Contexto, 2004. . O Lugar no/do Mundo. São Paulo: FFLCH, 2007. 85 p

CORDEIRO, H. K. A "Cidade Mundial" de São Paulo e a recente expansão do seu centro metropolitano. Revista Brasileira de Geografia. Rio de Janeiro: 54 (3): 5-26, jul./set. 1992. 


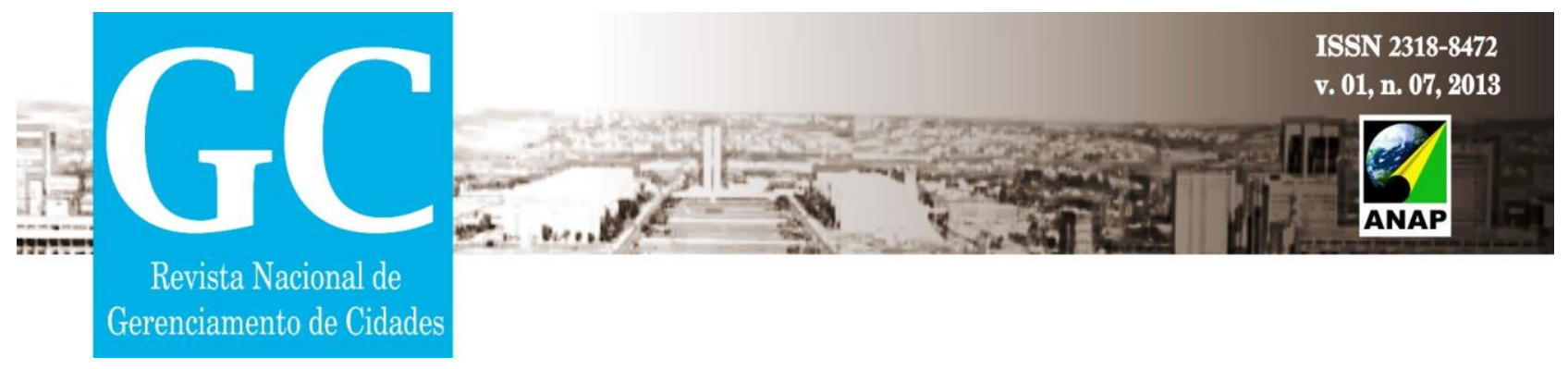

CORRÊA, R. L. O espaço urbano. 3ª ed. São Paulo: Ática, 1995.

Trajetórias Geográficas. Rio de Janeiro: Bertrand Brasil, 1997.

FERRAZ, A. C.; TORRES, .; G. E. Transporte público Urbano. São Carlos: 2004.

IBGE. População. Disponível em: <www.ibge.gov.br>. Acesso em 20 de Outubro de 2012.

KEINERT, T. M.M. Qualidade de Vida, Planejamento e Gestão Urbana. Rio de Janeiro: Bertrand Brasil, 2009.

LEFEBVRE, H. O direito à cidade. 4ª ed. São Paulo: Centauro, 2006.

BRASIL. LEI № 12.587, de 3 de janeiro de 2012. Politica Nacional de Mobilidade Urbana Sustentável. Disponível em: < http://www.planalto.gov.br/ccivil_03/_ato20112014/2012/lei/l12587.htm >. Acesso em: 20 de Outubro de 2012.

LOPES, V. M. Q. V. Uberlândia: histórias por entre trilhas, trilhos e outros caminhos: memórias, construção e apropriação dos espaços. Uberlândia: EDUFU, 2010.

MARICATO, E. As ideias fora do lugar e o lugar fora das ideias - planejamento urbano no Brasil. In: A cidade do pensamento único: desmanchando consensos. Org. ARANTES, O. VAINER, C.; , MARICATO, E. Petrópolis, Rio de Janeiro: Vozes, 2000. p. $121-192$.

. Metrópole, legislação e desigualdade. Estudos avançados, V. 17 ํo 48, Mai./Ago. 2003, Universidade de São Paulo, Instituto de Estudos Avançados da Universidade de São Paulo, p. 151-166.

MOTA, S. Urbanização e Meio Ambiente. Rio de Janeiro: ABES, 1999.

Prefeitura Municipal de Uberlândia. Norma Brasileira ABNT NBR 9050. Disponível em < http://www.uberlandia.mg.gov.br/midia/documentos/planejamento_urbano/norma_abnt_ac ess.pdf >. Acesso em: 01 de Junho de 2012.

RIBEIRO, F, V. A Área Central e sua Dinâmica: uma discussão. Sociedade \& Natureza, V. 16 no 31 , Dez. 2004, Universidade Federal de Uberlândia, Instituto de Geografia/EDUFU, p. 155-167.

SANTOS, M. A Natureza do Espaço: Técnica e Tempo, Razão e Emoção. 4. ed. São Paulo: Edusp, 2008. 392 p. 


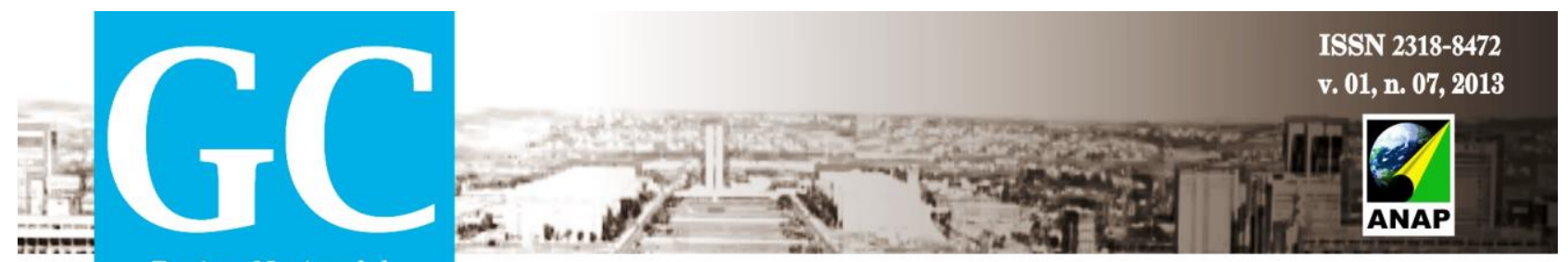

Revista Nacional de

Gerenciamento de Cidades

Metamorfoses do espaço habitado: fundamentos teórico metodológicos da Geografia. 6 ed. São Paulo: Editora USP, 2008.

O lugar encontrando o futuro. In: . Da totalidade ao lugar. São Paulo: USP, 2005. p. 155-163.

Território e Sociedade. Entrevista com Milton Santos. 2‥ ed. São Paulo: Fundação Perseu Abramo, 2004. 